\title{
Fatores de risco no tratamento de lesões do ceco com sutura primária em ratos ${ }^{1}$
}

\author{
Risk factors on the treatment of cecum injuries with primary suture in rats
}

\author{
Gustavo Pereira Fraga ${ }^{2}$, Mario Mantovani ${ }^{3}$, Rosana Celestina Morandin ${ }^{4}$, Cristiane Pereira Gomes ${ }^{5}$, Luís Alberto \\ Magna $^{6}$, Wagner Mauad Avelar ${ }^{7}$, Lucas Marcelo Dias Freire ${ }^{7}$
}

1. Pesquisa desenvolvida no Laboratório de Investigação de Cirurgia do Trauma (LICIT) da Disciplina de Cirurgia do Trauma do Departamento de Cirurgia da Faculdade de Ciências Médicas (FCM) da Universidade Estadual de Campinas (Unicamp), no Núcleo de Medicina e Cirurgia Experimental (NMCE). Resumo de Tese de Mestrado defendida e aprovada no Curso de Pós-Graduação em Cirurgia da FCMUnicamp.

2. Professor Assistente Doutor da Disciplina de Cirurgia do Trauma da FCM-Unicamp e do Departamento de Cirurgia do Hospital Municipal "Dr. Mário Gatti", Campinas-SP.

3. Professor Titular e Chefe da Disciplina de Cirurgia do Trauma da FCM-Unicamp.

4. Bióloga Doutora do Laboratório de Investigação de Cirurgia do Trauma (LICIT).

5. Médica Assistente do Departamento de Anatomia Patológica da FCM-Unicamp.

6. Professor Titular do Departamento de Genética Médica da FCM-Unicamp.

7. Médico Residente da FCM-Unicamp.

\section{RESUMO}

Objetivo: O presente trabalho teve como objetivo avaliar os resultados da sutura primária no tratamento das lesões traumáticas de ceco em ratos, após exposição a intervalos de tempo crescentes entre o trauma e a cirurgia, e com diferentes graus de peritonite. Métodos: Em estudo randomizado, duplo-cego, 96 ratos Wistar, machos, com peso variando de 200 a 250 gramas, foram submetidos a laparotomia, em que se realizava lesão de 5 milímetros de diâmetro na borda contramesentérica do ceco. Em 12 animais do grupo-controle realizava-se de imediato sutura primária com pontos totais, separados, com fio de polipropileno 7.0. Nos demais grupos, com 12 animais cada, a laparotomia para reparo da lesão foi realizada após intervalos de: 30 minutos, $1,2,4,6,9$ e 12 horas. No momento do reparo da lesão, uma das suas bordas era ressecada e enviada para exame anatomopatológico. Foi feito controle diário no pós-operatório, atentando-se para a presença de complicações, em especial deiscência da sutura, sendo a eutanásia dos animais realizada no $1^{\circ}, 4^{\circ}, 7^{\circ}$ e $14^{\circ}$ dia de pós-operatório. Em todos animais foi realizada necropsia, atentando-se aos achados macroscópicos e microscópicos do local da sutura. Resultados: Não houve associação entre a demora para o tratamento cirúrgico da lesão e a evolução para graus mais avançados de peritonite. A mortalidade nos 14 animais com peritonite difusa foi de 100\%. A mortalidade global foi de 25\% (24 animais), sendo que 6 animais (25\% dos óbitos) morreram antes do tratamento. Nenhum dos animais tratados que evoluíram a óbito teve complicação relacionada com a sutura da lesão. Os óbitos foram precoces, decorrentes de peritonite e sepse. Entre os 72 ratos sobreviventes, observou-se deiscência da sutura em 9 animais (12,5\%). A ocorrência desta complicação foi maior em animais operados a partir da sexta hora após o trauma, sendo os resultados estatisticamente significativos. A incidência de deiscência também foi maior nos ratos que apresentavam contaminação fecal mais intensa da cavidade peritoneal. A intensidade da peritonite no momento da sutura observada no exame histológico não teve associação com a ocorrência de complicações da sutura primária. Conclusão: A sutura primária é um procedimento de risco para tratar ratos, transcorrido intervalo superior a seis horas após o trauma, ou na vigência de contaminação intensa da cavidade por fezes.

Descritores: Lesões abdominais. Cólon. Ferimentos e Lesões. Trauma. Peritonite Experimentção Animal.

\begin{abstract}
Purpose: Analyze the results of primary suture in the treatment of cecum traumatic injuries in rats, after the exposure to increasing time intervals between the trauma and the surgery and with different peritonitis degrees. Methods: In a randomized double-blinded study, 96 Wistar male rats, weight ranging between 200 and 250 grams, underwent laparotomy, in which a 5milimiter-diameter-injury in the contramesenteric edge of the cecum was performed. In 12 animals of the control-group a prompt primary suture was executed, with total and separated stitches, with 7.0 polypropylene thread. In the other groups, with 12 animals each, a laparotomy for repair of the injury was executed after intervals of 30 minutes, 1, 2, 4, 6, 9 and 12 hours. At the time of injury repair, one of its edges was ressected and sent for anatomopathological examination. A daily control after the surgery was done, observing the presence of complications, specially dehiscence of the suture, and the euthanasia of the animals were done in the $1^{\text {st }}, 4^{\text {th }}, 7^{\text {th }}$ and $14^{\text {th }}$ day after the surgery. Necropsy was executed in all animals, observing the macroscopic and microscopic findings in the area of suture. Results: There was no association between the delay for surgical treatment of the injury and peritonitis degrees. The mortality in the 14 animals with diffuse peritonitis was 100\%. Global mortality was $25 \%$ (24
\end{abstract}


animals), and 6 animals (25\%) died before treatment. None of the animals treated that evolved to death had complications related to the suture of the injury. These early deaths were due to peritonitis and sepsis. Among the 72 surviving rats, there was dehiscence of the suture in 9 animals (12.5\%). This complication was statistically significant greater in animals operated on after the sixth hour following the trauma. The incidence of dehiscence was also greater in the rats presenting more intense fecal contamination. Intensity of the peritonitis at the moment of suture observed in histological examination had no association with the occurrence of complications of the primary suture. Conclusion: The primary suture as a risky procedure to treat rats, after an interval superior to six hours after the trauma or in the period of intense contamination of the cavity by feces.

Key words: Abdominal injuries. Colon. Wounds and Injuries. Trauma.Peritonitis. Animal Experimentation.

\section{Introdução}

O tratamento das lesões traumáticas do cólon continua sendo motivo de controvérsias. O reparo primário da lesão é o procedimento adotado na maioria dos traumas colônicos, independente dos fatores de risco associados, porém, na presença de alguns destes fatores, a realização de colostomia pode ser uma conduta mais segura.

A publicação da experiência de Stone e Fabian ${ }^{1}$, em 1979, foi fundamental para definir os fatores de risco que, quando presentes, direcionavam o cirurgião para a realização de uma colostomia. Nas duas últimas décadas, vários artigos foram publicados e revelaram as controvérsias em relação aos fatores de risco que contra-indicam ou não a realização de sutura primária em lesões traumáticas do cólon. Os fatores de risco que têm gerado polêmicas na literatura são: idade do paciente, presença de choque hipovolêmico, quantidade de sangue transfundido, tempo transcorrido entre o trauma e a cirurgia, grau de contaminação peritoneal, segmento do cólon lesado, lesão associada em outros órgãos e extensão da lesão do cólon. $\mathrm{Na}$ presença destes fatores de risco pode ocorrer deficiência na cicatrização de uma sutura ou anastomose intestinal. A evolução com deiscência ou fístula do cólon, seguido de abscesso ou peritonite, pode ser fatal se não for precocemente diagnosticada e tratada.

Analisando apenas trabalhos prospectivos, em que 127 pacientes foram tratados com sutura primária sem critérios de exclusão, alguns autores identificaram complicações da sutura em 2 casos $(1,6 \%)^{2-4}$. Curran e Borzotta ${ }^{5}$ concluíram que os traumas penetrantes e fechados do cólon na vida civil são tratados seguramente com o reparo primário, mas a colostomia ainda é aconselhada em casos selecionados, sendo esta opinião também compartilhada por outros autores $\mathrm{em}^{6,7}$. Porém, Chappuis e col. ${ }^{2}$, Sasaki e col. ${ }^{3}$ e Gonzalez e col. ${ }^{4}$, em estudos recentes, prospectivos e randomizados, mostraram que o reparo primário deve ser o tratamento de escolha para as lesões traumáticas do cólon, independentemente da presença de qualquer fator de risco, mesmo que associado. Resta-nos saber se devemos adotar rotineiramente esta conduta, como indicam as tendências na literatura, ou ainda indicar a colostomia em casos de exceção.

O presente estudo avalia dois fatores de risco que geram dúvidas quanto à indicação absoluta de sutura primária. O objetivo foi verificar se a realização de reparo primário, no tratamento das lesões traumáticas penetrantes do cólon, pode ser seguida com segurança. Para tanto, por meio de estudo experimental em ratos, foram analisados os aspectos envolvidos na ocorrência de complicações relacionadas à sutura primária do ceco, em especial deiscência de sutura, em animais expostos a dois fatores de risco críticos: intervalos de tempo crescentes entre o trauma e o tratamento cirúrgico, e diferentes graus de contaminação peritoneal. O local do intestino escolhido na pesquisa, para a realização da lesão, foi o ceco, seguindo modelo descrito por Fraga e col. ${ }^{8}$. As complicações foram avaliadas através da observação clínica e exame histopatológico.

\section{Métodos}

A pesquisa foi aprovada pela Comissão de Ética na Experimentação Animal do Instituto de Biologia da Unicamp.

Foram utilizados 96 ratos da linhagem Wistar com padrão sanitário SPF ("Specific Pathogen Free"), fornecidos pelo Centro de Bioterismo (CEMIB) da UNICAMP. Todos os animais eram machos e foram alimentados com ração Nuvilab ${ }^{\circledR}$ e água filtrada ad libitum. O peso do animal para inclusão na experiência variou de 200 a 250 gramas, enquanto que a idade variou de 49 a 70 dias, com média de 57,5 dias. A temperatura e a umidade ambientais do biotério não eram controladas, e o fotoperíodo foi programado em 12 horas-luz e 12 horas-escuro.

O traumatismo do ceco do animal foi feito após uma laparotomia. No pré-operatório os ratos foram mantidos com dieta livre, não havendo qualquer tipo de preparo intestinal. $\mathrm{O}$ animal era anestesiado com éter etílico inalatório, até atingir o plano anestésico, que era caracterizado pela analgesia e relaxamento muscular suficientes para os procedimentos cirúrgicos, constituindo-se no Estágio 3 e Plano 2, descritos por Kohn e col. . . O animal era colocado numa prancha cirúrgica apropriada e realizava-se a antissepsia com solução de álcool iodado a $2 \%$, seguida da colocação de campo fenestrado. Realizava-se a laparotomia através de incisão longitudinal mediana, que media de 1,7 a 2,5 centímetros de extensão. Após a abertura da cavidade peritoneal, era identificado e tracionado o ceco. A lesão perfurante era feita na borda contramesentérica, na extremidade distal, a 1 centímetro da válvula ileocecal, conforme descrito por Fraga e col. ${ }^{8}$. O fragmento do ceco excisado era encaminhado para estudo histológico, constituindo-se na Biópsia A. Registrava-se o diâmetro da lesão (5 ou 6 milímetros) e não era feito hemostasia ou controle da contaminação local. O ceco era recolocado na cavidade peritoneal e a parede abdominal fechada em dois planos.

No pós-operatório imediato o animal era recolocado em outra gaiola, sendo que os 12 ratos do grupo controle, 
denominado de $\mathrm{G}$ 0, tiveram a lesão reparada neste mesmo tempo cirúrgico, com acesso imediato à dieta via oral líquida, livre demanda, com soro glico-fisiológico. Os animais dos demais grupos eram mantidos em jejum até o reparo do traumatismo do ceco.

A fim de tornar o estudo randomizado e "duplo cego", o pesquisador desconhecia todas as informações referentes à cirurgia da lesão intestinal, inclusive o horário da mesma, exceto nos grupos $\mathrm{G} 0$ e o de animais tratados 30 minutos após a lesão (G 30). Tais informações eram de domínio apenas da bióloga que, após a cirurgia do traumatismo do cólon, distribuía os animais em um dos seis grupos abaixo especificados, com 12 ratos cada grupo, variando o intervalo de tempo para tratamento da lesão: G 1, 1 hora; G 2, 2 horas; G 4, 4 horas; G 6, 6 horas; G 9, 9 horas; e G 12, 12 horas.

Todas as cirurgias para tratamento da lesão traumática do animal foram feitas pelo pesquisador. Os animais foram submetidos à anestesia geral por meio da punção de veia caudal e injeção de pentobarbital sódico (Sagatal $\left.{ }^{\circledR}\right)$, na dose de 50 miligramas para cada quilograma de peso corpóreo. Era mantida a venóclise com o cateter heparinizado, a fim de se repetir em doses suplementares de anestésico, conforme a necessidade, a fim de manter o animal no plano anestésico Estágio 3 e Plano $2^{9}$. Os animais eram mantidos com ventilação espontânea e a laparotomia era feita sobre a incisão já existente, porém mais extensa, com 2,7 a 6,5 centímetros de extensão. No inventário da cavidade peritoneal era observado e registrado o grau de contaminação, sendo assim classificado: peritonite difusa (presença de conteúdo fecal ou purulento nos quatro quadrantes da cavidade), contaminação moderada (restrita até a dois quadrantes da cavidade peritoneal) ou contaminação pequena (no local da lesão).

Após o inventário, nos casos de contaminação difusa da cavidade peritoneal, procedia-se à limpeza da cavidade com gaze e soro fisiológico a $0,9 \%$, com temperatura variando entre 38 e $40^{\circ} \mathrm{C}$, antes de se abordar a lesão. Seguia-se com a tração do ceco para fora da cavidade e com a malaxação distal do conteúdo fecal. Fazia-se a limpeza do local da lesão com soro fisiológico a $0,9 \%$, colocava-se uma pinça coprostática e realizava-se o desbridamento de uma das bordas da lesão, que era submetida à análise anatomopatológica e denominada de Biópsia B.

A sutura primária da lesão foi realizada com pontos simples separados e totais. Os pontos eram paralelos e eqüidistantes dois milímetros um do outro, com os nós voltados para fora do lume intestinal, tomando-se o cuidado para não apertá-los excessivamente, obtendo-se apenas justaposição das referidas túnicas, evitando-se inversão ou eversão das bordas. O fio cirúrgico utilizado foi o polipropileno 7.0, monofilamentar, não absorvível, com agulha cilíndrica de um centímetro, atraumática.

Uma vez terminada a sutura, era realizada a lavagem de toda a cavidade peritoneal com soro fisiológico $0,9 \%$. O fechamento da cavidade peritoneal era realizado em dois planos, ambos com sutura com fio de polipropileno 3.0.

Após a cirurgia para tratamento da lesão intestinal e da recuperação anestésica, o animal era colocado em gaiola coletiva, com no máximo 4 animais já operados em cada gaiola. Nas primeiras horas de pós-operatório até o dia seguinte eram alimentados com soro glicofisiológico, permanecendo sob a vigilância do pesquisador. A partir do primeiro dia pósoperatório os animais eram reconduzidos ao biotério, sendo iniciada a dieta com ração e água ad libitum. Diariamente avaliava-se a distensão abdominal, o aspecto da incisão cirúrgica e registrava-se o peso dos animais. O seguimento de cada animal era feito até o óbito, ou até o momento da eutanásia, realizada conforme a randomização estabelecida.

Os animais que evoluíam a óbito eram submetidos de imediato à necropsia, quando se realizava o exame macroscópico da cavidade peritoneal e das suturas. As necropsias eram feitas sem técnica asséptica e o ceco era ressecado para estudo anatomopatológico. Conforme o momento em que ocorria o óbito, este era classificado como imediato, precoce ou tardio. Os óbitos eram considerados imediatos se ocorressem antes ou durante a cirurgia para tratamento da lesão, em conseqüência de sepse abdominal. Os óbitos foram definidos como precoces quando o êxito letal ocorria nas primeiras 24 horas de pós-operatório da cirurgia para reparo da lesão do ceco, e eram classificados como óbitos tardios caso ocorressem após este período.

Ao término da cirurgia para tratamento da lesão, realizava-se sorteio, no qual três ratos de cada grupo $(0,30,1$, 2, 4, 6, 9 e 12) eram incluídos em um dos subgrupos, com até 24 animais cada (excluídos os óbitos), conforme o dia pósoperatório programado para a eutanásia: grupo A, sacrifício no $1^{\circ}$ dia pós-operatório; grupo $\mathrm{B}$, sacrifício no $4^{\circ}$ dia pósoperatório; grupo $\mathrm{C}$, sacrifício no $7^{\circ}$ dia pós-operatório; e grupo $\mathrm{D}$, sacrifício no $14^{\circ}$ dia pós-operatório.

Nos animais com boa evolução pós-operatória, a eutanásia era realizada por meio de uma overdose inalatória de éter sulfúrico, no dia programado. Na necropsia procediase inicialmente ao exame macroscópico da cavidade peritoneal, seguido da avaliação externa da lesão do ceco suturada, com ressecção do mesmo para análise do material à microscopia óptica, sendo a peça cirúrgica denominada de Biópsia C.

Durante a necropsia, foram consideradas complicações diretamente relacionadas à sutura da lesão do ceco: deiscência parcial da sutura com pequeno abscesso localizado na área do bloqueio de órgãos ou estruturas abdominais; fístula ou deiscência completa da sutura primária, incluindo-se fístulas enterocutâneas; peritonite difusa em animal necropsiado a partir do $4^{\circ}$ dia pós-operatório, uma vez que nos casos de óbito precoce a peritonite era secundária à contaminação da cavidade peritoneal após a lesão, e não decorrente de falha na sutura primária.

No pós-operatório foram avaliados vários parâmetros: mortalidade, complicações diretamente relacionadas à sutura da lesão e complicações gerais.

O exame histológico foi realizado no Laboratório de Anatomia Patológica do Núcleo de Medicina e Cirurgia Experimental da Unicamp. As peças cirúrgicas foram fixadas em solução de formalina a $10 \%$, incluídas em blocos de parafina e submetidas a cortes de 5 micra de espessura, e depois corados com hematoxilina-eosina (HE). O estudo anatomopatológico foi feito em três momentos diferentes, em cada animal, sendo: 
biópsia A, B e C.

No estudo histológico foram avaliados os seguintes parâmetros: presença e intensidade da peritonite fecal, e a fase da reação inflamatória (aguda, subaguda ou crônica). Estas avaliações tiveram como finalidade detectar eventual associação entre a presença de complicações da sutura primária e os achados histológicos, bem como a evolução do processo de cicatrização no ceco.

Conforme a natureza das variáveis estudadas, utilizaram-se os seguintes testes para análise dos resultados: teste de Kruskal-Wallis, teste de Mann-Whitney, teste exato de Fisher, teste do qui-quadrado, e teste de correlação de Pearson, utilizado para verificar a evolução em função do tempo.

O Organograma ilustra resumidamente como foi desenvolvida a pesquisa.

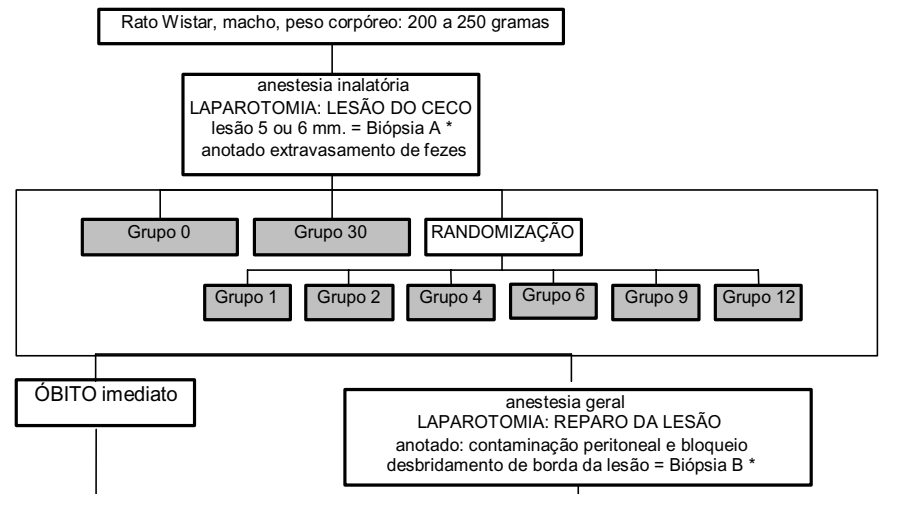

Resultados

A cirurgia para reparo da lesão no ceco foi feita em 90 animais, uma vez que 6 ratos morreram antes de serem tratados.

No inventário da cavidade abdominal, todos os animais do grupo-controle ( $G$ o) não apresentavam contaminação fecal ou bloqueio da lesão. Nos 84 animais dos outros grupos o grau de contaminação da cavidade peritoneal encontrado foi: peritonite difusa em 14 ratos $(16,7 \%)$, contaminação moderada em $14(16,7 \%)$ e contaminação pequena em 56 animais $(66,6 \%)$. Entre os 14 animais que apresentavam peritonite difusa estão incluídos os 6 que evoluíram a óbito antes da cirurgia para tratamento da lesão, considerados como óbitos imediatos. A Figura 1 mostra o número de animais nos diferentes grupos, que representam o intervalo de tempo transcorrido para tratar a lesão, e o grau de contaminação encontrado. Utilizando-se o teste de Pearson, observou-se que não houve correlação direta entre a demora para o tratamento cirúrgico da lesão e a evolução para estágios mais avançados de peritonite nos animais operados a partir da primeira hora após o trauma.

Em relação à formação de aderências e tamponamento da lesão, nos 90 animais $(93,7 \%)$ operados registrou-se a intensidade do bloqueio e verificou-se que com o passar das horas o animal acabava tamponando a lesão, com intensidade de bloqueio cada vez maior, com correlação diretamente

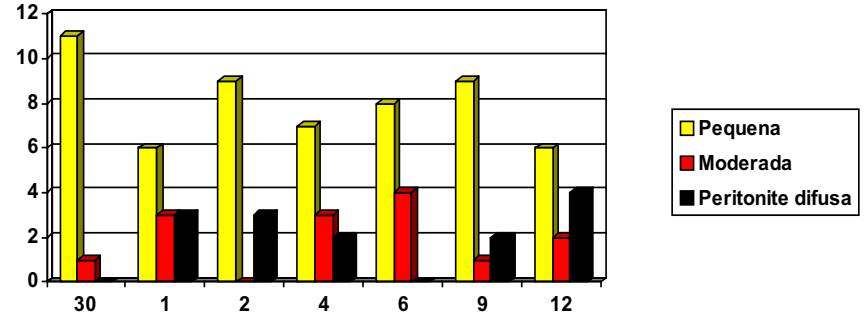

FIGURA 1 - Número de animais, conforme o grau de contaminação peritoneal encontrado na cirurgia para tratamento da lesão, nos diferentes grupos

proporcional ao tempo (teste de correlação de Pearson). Nos 39 animais em que havia um bloqueio intenso sobre a lesão, em 36 deles $(92,3 \%)$ a peritonite foi classificada como pequena e nos outros $3(7,7 \%)$, a peritonite era moderada. Não ocorreu peritonite difusa nos ratos que apresentavam bloqueio intenso. O epíploon foi a estrutura abdominal mais envolvida no bloqueio, fazendo-se presente em 39 ratos $(66,1 \%)$.

A duração da cirurgia para reparo da lesão foi em média de 25 minutos nos animais do Grupo 0, cujo abdome já se encontrava aberto e não havia contaminação importante da cavidade peritoneal. Nos demais grupos, o tempo cirúrgico variou de 24 a 75 minutos, com média de 42 minutos.

A mortalidade global da lesão do ceco nos ratos foi de 25\% (24 animais), sendo os óbitos classificados como: imediatos (6 ratos $-25 \%$ dos óbitos), precoces ( 17 ratos $-70,8 \%$ ) ou tardio (1 rato - 4,2\%). A Figura 2 mostra a distribuição dos óbitos conforme o intervalo de tempo após o tratamento.

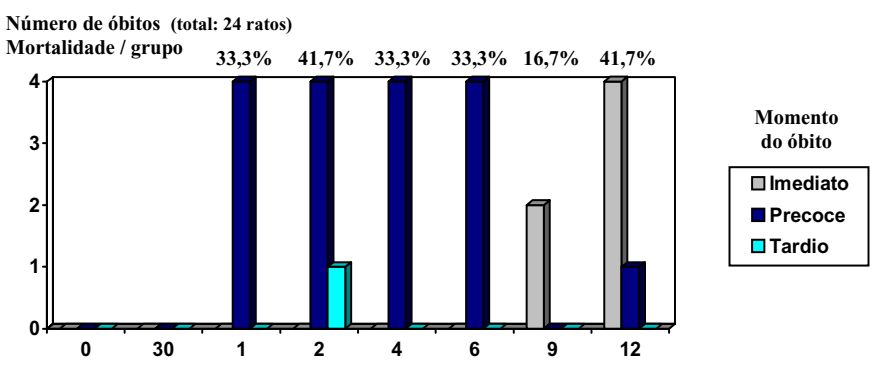

FIGURA 2 - Número de animais que evoluíram a óbito e respectiva porcentagem, nos diferentes grupos, conforme o momento do óbito

Os 6 animais $(6,3 \%)$ que morreram antes do tratamento definitivo, ou seja, óbitos imediatos, eram do Grupo 9 (2 animais) ou Grupo 12 (4 animais). Durante a necropsia notou-se que todos estes animais apresentavam peritonite fecal intensa e em 3 deles (50\%) não havia bloqueio sobre o ceco suturado. Estes óbitos ocorreram num período de 6 a 12 horas após a lesão. A maioria dos animais que evoluíram a óbito (17 ratos) foi incluída no grupo de óbitos precoces. Não ocorreu nenhum óbito nos Grupos 0, 30 e 9 após o tratamento da lesão. Nos animais dos grupos 1, 2, 4, e 6 a taxa de óbitos precoces foi de $33,3 \%$ em cada um destes grupos, mostrando que não houve diferença na mortalidade ao se tratar estes animais num período de 1 a 6 horas após o trauma (Figura 2). Já nos animais do Grupo 12 ocorreu um único óbito, que somado aos 4 animais que haviam morrido antes do tratamento resultaram numa 
mortalidade de 41,7\% neste grupo. Em relação à mortalidade, foi aplicado o teste de Fisher e nos 72 animais operados a partir da primeira hora após o trauma constatou-se uma mortalidade significativamente maior $\left(\mathrm{p}=0,0006^{*}\right)$, se comparada aos 24 animais dos Grupos 0 e 30.

Em todos os animais que evoluíram a óbito o achado intraperitoneal, durante a necropsia, foi de pequena quantidade de líquido seroso, compatível com peritonite. Em nenhum destes ratos havia fístula da sutura primária da lesão e foi inferido como causa mortis destes animais a infecção abdominal, que evoluiu para choque séptico.

Houve um único caso de óbito considerado como tardio, que foi um animal do Grupo 2, o qual evoluiu com infarto do cólon. Este animal morreu no $3^{\circ}$ dia pós-operatório, não sendo considerado este óbito como secundário à complicação do reparo primário, estando a sutura íntegra no exame de necropsia. Portanto, nenhum dos 24 animais que evoluíram a óbito nesta casuística foi em conseqüência do reparo primário, resultando conseqüentemente numa mortalidade de $0 \%$ diretamente relacionada à sutura do ceco. Observou-se que em todos animais que evoluíram a óbito a causa foi a sepse de origem abdominal. A Figura 3 mostra o aspecto da cavidade peritoneal no momento da cirurgia para reparo da lesão e a mortalidade associada. Todos os animais que apresentavam peritonite difusa evoluíram a óbito.

Número de animais (total: 84 ratos) / mortalidade

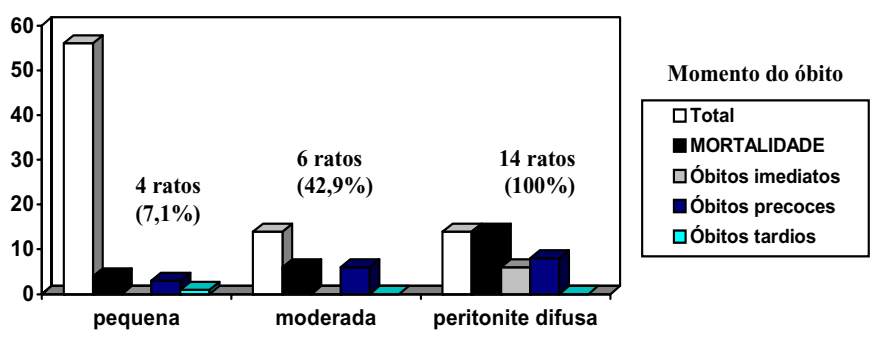

FIGURA 3 - Número de animais e porcentagem conforme o grau de contaminação peritoneal encontrado na cirurgia, a mortalidade e o momento do óbito

Nos animais que evoluíram a óbito (24 ratos - 25\%) não se constatou complicação secundária ao reparo da lesão, como fístula ou deiscência da sutura. Entre os 72 animais (75\%) que foram submetidos à eutanásia, durante a necropsia observaram-se complicações diretamente relacionadas à sutura da lesão em 9 animais (12,5\%). Estas complicações foram: fístula ou deiscência completa da sutura em 4 animais $(44,4 \%)$ e deiscência parcial em 5 animais $(55,6 \%)$, estando associadas a abscesso intraperitoneal em 7 ratos $(77,8 \%)$. Em 2 animais a deiscência era pequena, estando bem bloqueada, sendo que os mesmos foram submetidos à eutanásia no $4^{\circ}$ dia pós-operatório e não havia ainda abscesso intraperitoneal. Dentre os 9 ratos que tiveram complicações, em $7(77,8 \%)$ a eutanásia foi feita no $4^{\circ}$ dia pós-operatório e nos outros $2(22,2 \%)$, fez-se o sacrifício após 7 dias de tratamento.

A Figura 4 ilustra as complicações relacionadas à sutura da lesão nos diferentes grupos. Houve uma maior incidência de complicações nos ratos tratados num intervalo de tempo, após o trauma, igual ou superior a 6 horas, sendo estes valores, de acordo com o teste exato de Fisher, estatisticamente significativos $\left(\mathrm{p}=0,0015^{*}\right)$.

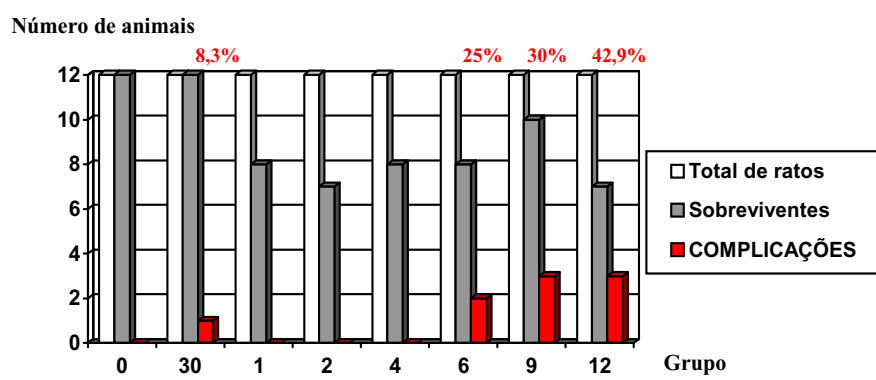

FIGURA 4 - Número de animais sobreviventes que evoluíram para complicações diretamente relacionadas à sutura primária nos diferentes grupos

Comparando-se o grau de peritonite no momento da cirurgia para reparo da lesão, observou-se que nos 9 animais que apresentaram complicações relacionadas à sutura, em 5 deles $(55,6 \%)$ a contaminação da cavidade era mínima, restrita apenas ao local da lesão, enquanto que nos outros 4 (44,4\%) já havia uma contaminação moderada. Em contrapartida, a incidência de complicações foi de $7,8 \%$ nos 64 animais sobreviventes, que tinham contaminação mínima, contra $50 \%$ de morbidade diretamente relacionada à sutura nos 8 animais sobreviventes com contaminação moderada, mostrando uma associação estatisticamente significativa entre o grau de peritonite e a presença de complicações da sutura primária, conforme obtido pelo teste do qui-quadrado $\left(\mathrm{p}=0,0046^{*}\right)$.

Além das complicações já citadas, outras denominadas menores foram observadas em cinco animais, sendo: infecção da ferida operatória em quatro e sub-oclusão intestinal em um rato necropsiado no $1^{\circ}$ dia pós-operatório. Isto resultou numa morbidade global de 39,6\% (38 ratos tiveram complicações, incluindo todos que evoluíram a óbito). Entre os 72 animais que sobreviveram, só sendo submetidos à eutanásia previamente programada, a taxa de complicações foi de 19,4\% (14 ratos), correspondendo à deiscência da sutura primária em nove animais e complicações menores em 5 ratos.

Nos 96 animais foi realizado o exame histológico da Biópsia A, sendo que em todas estas amostras o ceco tinha todas as túnicas com aspecto característico, dentro dos padrões da normalidade.

A Biópsia B foi realizada nos 90 animais submetidos a tratamento cirúrgico, porém o material obtido em 20 animais $(22,2 \%)$ foi considerado como escasso, impossibilitando a emissão de laudo pela patologista. Nos 70 animais em que foi feita a Biópsia B, em todos havia peritonite, sendo graduada como leve em $61(87,1 \%)$, moderada em $7(10 \%)$ e intensa em 2 animais (2,9\%). Entre os 9 animais que evoluíram para complicações diretamente relacionadas à sutura primária, em $8(88,9 \%)$ a Biópsia B foi examinada. Seis ratos $(75 \%)$ apresentavam peritonite leve e outros $2(25 \%)$ tinham peritonite moderada ao exame microscópico, no momento da sutura da lesão. A intensidade da peritonite no exame histológico não 
teve associação com a ocorrência de complicações da sutura primária, sendo que os dois animais que tinham peritonite intensa tiveram boa evolução no pós-operatório.

A Biópsia $\mathrm{C}$ foi realizada em todos animais. Em 24 ratos $(25 \%)$ observou-se autólise ao exame microscópico, sendo exatamente estes os animais que evoluíram a óbito. Nos 72 ratos que tiveram evolução satisfatória no pós-operatório, a Biópsia $\mathrm{C}$ foi obtida pela eutanásia dos animais nos dias previamente programados. Na Biópsia C identificou-se cicatrização da sutura cecal em diferentes fases da reação inflamatória (aguda, subaguda e crônica), que variaram conforme o dia em que foi feita a necropsia. Nos animais dos Grupos A e B havia processo inflamatório, próprio da cicatrização em fase aguda e de modo mais intenso. Já nos Grupos C e D a intensidade da peritonite era geralmente leve ou moderada, e a peritonite era crônica em quase todos os animais.

\section{Discussão}

Em várias situações clínicas pode ocorrer deficiência na cicatrização de uma sutura ou anastomose: nos pacientes idosos, nos desnutridos, nos diabéticos, nos ictéricos, nos pacientes com déficit de vitaminas, nos urêmicos, nos usuários de corticoterapia ou outras drogas imunossupressoras ${ }^{10}$. Os fatores locais que têm sido freqüentemente estudados na área experimental e que também influenciam na cicatrização são: baixo fluxo sangüíneo com hipóxia tecidual, contaminação bacteriana, traumatismos associados, falha técnica no ato cirúrgico, fios de sutura utilizados, formação de aderências, presença de corpos estranhos e drenos ${ }^{10-23}$. O presente trabalho avaliou a infecção intraperitoneal como fator de risco na cicatrização de suturas do ceco em ratos.

No pré-operatório não foi feito qualquer tipo de preparo do cólon. Sabe-se que o cólon do rato geralmente encontra-se vazio após 24 horas de jejum ${ }^{24}$. Smith e col. ${ }^{24}$ estudaram o efeito do conteúdo fecal na cicatrização de anastomoses no cólon esquerdo de ratos e observaram uma maior incidência de deiscência nos animais em que o cólon estava repleto de fezes, no momento da cirurgia. No presente trabalho os animais não foram mantidos em jejum, a fim de mimetizar o que geralmente acontece com o traumatizado, que é operado de urgência e sem preparo pré-operatório.

Em relação à anestesia, optou-se pelo uso do éter por via inalatória na cirurgia para lesão do ceco. Embora esta anestesia atualmente seja criticada em trabalhos experimentais, ainda é a adotada por muitos pesquisadores ${ }^{13,14,16,17,19,21,22,23,25,26}$. A escolha pela anestesia inalatória foi devida aos seguintes aspectos: cirurgia rápida, o plano anestésico desejado era facilmente atingido e controlado, e a recuperação pós-anestésica do animal também ocorria rapidamente, o que não interferia na randomização. Houve um único caso de óbito durante a indução anestésica, sendo este animal excluído da casuística. Também na cirurgia para tratamento da lesão do ceco, em que se utilizou a injeção intravenosa de pentobarbital sódico, não houve dificuldade para manutenção do plano anestésico estabelecido.
Outro fator que precisou ser bem padronizado foi o tamanho da lesão do ceco. Isto posto, julgou-se necessário a realização de um estudo experimental preliminar em ratos, a fim de observar a resposta destes animais a diferentes graus de lesão ${ }^{8}$. Chamou a atenção a capacidade do rato de bloquear a lesão, que não foi fatal, após sete dias de acompanhamento em $1 / 3$ dos animais com lesão extensa.

Após a cirurgia para realização da lesão no ceco, o animal era sorteado e incluído em um dos grupos, conforme o momento do tratamento definitivo. O pesquisador desconhecia o grupo do rato que era operado, exceto nos animais do Grupo 0 , que na mesma laparotomia para lesar o ceco já eram submetidos à sutura primária, e os ratos do Grupo 30, que no momento da cirurgia terapêutica ainda encontravam-se em recuperação da anestesia inalatória. O objetivo desta randomização foi eliminar eventuais interferências quanto ao tratamento empregado.

No inventário da cavidade, na cirurgia para tratamento do animal, era registrada a intensidade da peritonite. Esta graduação foi feita pelo pesquisador em todos os animais, baseado na quantidade e disseminação do conteúdo fecal, sendo que isto foi influenciado pela resposta individual e capacidade de tamponamento da lesão em cada animal. Durante o inventário o pesquisador fazia um palpite do grupo ao qual pertencia o animal, conforme a intensidade da peritonite, sendo que só houve acerto em $22 \%$ dos animais. Assim sendo, na maioria das situações não era possível estabelecer uma correlação direta entre o intervalo de tempo para o tratamento da lesão e o grau de peritonite do animal operado, mostrando que a randomização foi eficiente ao prevenir possíveis interferências na pesquisa.

Em relação à mortalidade, foi detectado, no momento da necropsia, peritonite difusa em todos os 24 animais (25\%) que evoluíram a óbito, sendo a causa mortis atribuída ao choque séptico. Seis animais $(6,3 \%)$ morreram antes de ser tratados, sendo considerados óbitos imediatos. Fraga e col. ${ }^{8}$ observaram uma mortalidade de $40 \%$ em 15 ratos com lesão de 5 ou 6 milímetros de diâmetro no ceco, e que não foram submetidos a qualquer tipo de tratamento. Neste estudo preliminar, o óbito destes seis animais ocorreu num período que variou de 7 a 12 horas após o trauma, com média de 9 horas e 30 minutos. Isto posto, nota-se que a peritonite secundária a este tipo de lesão no ceco evolui rapidamente com sepse e óbito nos animais que não conseguem tamponar a lesão.

A mortalidade nos 90 animais que foram operados para reparo da lesão foi de $20 \%$ (18 ratos). Não ocorreu nenhum óbito nos Grupos 0 e 30, sendo que a mortalidade nos animais operados a partir da primeira hora após o trauma foi de $27,3 \%$ (dezoito óbitos em 66 animais). Ao analisar a mortalidade nos Grupos 1, 2, 4 e 6, composto por 12 animais cada, obtiveramse taxas que variaram em cada um destes grupos de 33,3 a $41,7 \%$, mostrando que não houve correlação direta entre o intervalo de tempo para tratamento da lesão e a evolução a óbito nestes grupos (Figura 2). Observou-se também que o tratamento com reparo primário em ratos, transcorrido uma hora após o trauma, aumenta de modo significativo a mortalidade, uma vez que nenhum dos animais dos Grupos 0 e 
30 evoluiu a óbito ( $\mathrm{p}=0,0006^{*}$ ). Nos animais operados do Grupo 9 não ocorreu nenhum óbito no pós-operatório, enquanto que nos ratos tratados do Grupo 12 a mortalidade foi de 12,5\%. É interessante esta menor taxa de mortalidade nos ratos tratados mais tardiamente, mas é provável que estes animais já tivessem tamponado a lesão por mecanismos intrínsecos, estando inclusive sujeitos a uma boa evolução, independentemente do tratamento adotado.

Em relação a causa mortis nestes animais, investigada na necropsia, em nenhum deles foram encontradas complicações relacionadas à sutura primária. Praticamente todos os animais morreram com menos de 24 horas após o tratamento, exceto um rato que macroscopicamente apresentava necrose do cólon, mas não tinha deiscência da sutura no momento do exame.

A sutura da lesão foi feita após o desbridamento de uma das bordas, enviada para exame anatomopatológico (Biópsia B). Vale ressaltar que na prática clínica o desbridamento das bordas da lesão é um procedimento de rotina nos traumas de cólon por projétil de arma de fogo.

No presente estudo optou-se pela sutura com pontos simples, separados e totais, como descrito por Gambee e col. ${ }^{27}$ e depois adotado por outros autores em trabalhos

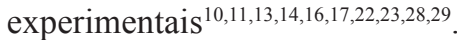

Após a sutura da lesão cecal, nos 90 animais que foram operados realizou-se a lavagem da cavidade peritoneal com soro fisiológico a $0,9 \%$ aquecido, até a remoção completa da secreção e do conteúdo fecal da cavidade. Tal procedimento foi sistematizado e obviamente que volumes maiores de solução se fizeram necessários em graus mais avançados de peritonite. Stewart e Matheson ${ }^{25}$ induziam a peritonite em ratos com uma suspensão de fezes diluídas e operavam o animal após uma hora para lavagem da cavidade. A mortalidade nos animais que foram operados e não foram submetidos a qualquer procedimento terapêutico foi de $100 \%$, sendo que em 24 animais em que se realizou apenas a remoção do conteúdo fecal e do exsudato da cavidade peritoneal com gazes a mortalidade também foi de $100 \%$. Nos 24 animais em que foi feita a lavagem da cavidade com solução salina houve redução da mortalidade para $54 \%$, sendo que taxas de óbito ainda menores foram obtidas com a associação de antibióticos no lavado peritoneal. Torres e col. ${ }^{26}$ também avaliaram a eficácia da lavagem da cavidade peritoneal com solução de cloreto de sódio a 0,9\%. Após induzirem a peritonite em ratos com homogeneizado de fezes humanas, observaram uma mortalidade de $100 \%$ nos animais que não foram tratados. Em outros dois grupos de ratos, com 12 animais cada, realizaram a laparotomia após 6 horas, sendo que num grupo fizeram a limpeza da cavidade com gaze estéril e a mortalidade foi de $50 \%$, enquanto que no outro grupo, em que a cavidade foi lavada com solução salina, não ocorreu nenhum óbito após 48 horas de observação. Isto posto, tornase evidente a eficácia da lavagem da cavidade peritoneal no tratamento da peritonite, sendo que no presente estudo este foi, além da sutura primária, o único procedimento empregado na terapêutica dos animais.

Na prática clínica, a deiscência ou fístula da sutura constitui-se no grande temor do cirurgião que indica o reparo primário para o tratamento das lesões traumáticas do cólon. A incidência de fístula da sutura primária varia de 0 a $6,1 \%$ (média: 2,4\%), dependendo do estudo avaliado, sendo importante considerar quais foram os critérios para incluir ou excluir o paciente no estudo, uma vez que na maioria dos trabalhos este procedimento ainda é indicado de modo seletivo ${ }^{5}$.

Em estudos experimentais em ratos, a incidência de fístula da sutura ou anastomose é variável, dependendo do segmento do cólon lesado e o fator de risco ao qual o animal foi exposto. Nos animais em que a sutura é realizada sem qualquer fator de risco, o que é representado na maioria dos estudos pelo grupo-controle, são raras as descrições de deiscência ou fístula no pós-operatório, como pode ser observado na Tabela 1.

TABELA 1 - Incidência de fístula em anastomoses do cólon esquerdo em estudos experimentais em ratos, conforme a exposição a diferentes fatores de risco

\begin{tabular}{|c|c|c|c|}
\hline AUTORES & FATOR DE RISCO & $\begin{array}{l}\text { Número } \\
\text { de ratos }\end{array}$ & $\begin{array}{c}\text { Fístula } \\
(\%)\end{array}$ \\
\hline \multirow[t]{5}{*}{ Irvin e Hunt ${ }^{16}$} & AUSENTE & 65 & 0 \\
\hline & trauma extra-abdominal & 28 & 0 \\
\hline & trauma intra-abdominal & 80 & 12,5 \\
\hline & trauma intra e extra-abdominal & 28 & 32,1 \\
\hline & trauma extra-abdominal + dreno & 27 & 22,2 \\
\hline \multirow[t]{2}{*}{$\operatorname{Irvin}^{15^{-}}$} & AUSENTE & 12 & 0 \\
\hline & peritonite (fezes de rato) & 13 & 46,2 \\
\hline \multirow[t]{2}{*}{ Jiborn e $\operatorname{col}^{34}$} & AUSENTE, sutura com pontos separados & 61 & 5 \\
\hline & AUSENTE, sutura contínua & 105 & 14,3 \\
\hline \multirow[t]{5}{*}{ Smith e $\operatorname{col}^{2 \sigma^{-}}$} & AUSENTE & 28 & 7,1 \\
\hline & dreno de latex & 28 & 71,4 \\
\hline & dreno de PVC & 28 & 32,1 \\
\hline & dreno de teflon & 28 & 25 \\
\hline & dreno de silastic & 28 & 25 \\
\hline \multirow[t]{4}{*}{ Czeczko e col ${ }^{22}$} & AUSENTE & 9 & 0 \\
\hline & peritonite (6 horas de evolução) & 10 & 20 \\
\hline & dreno de Penrose & 10 & 30 \\
\hline & peritonite + dreno de Penrose & 8 & 62,5 \\
\hline \multirow[t]{2}{*}{ Naresse e coll ${ }^{23^{*}}$} & AUSENTE & 120 & 0 \\
\hline & peritonite (6 horas de evolução) & 120 & 8 \\
\hline \multirow[t]{3}{*}{ Leite e $\mathrm{col}^{25}$} & AUSENTE & 85 & 0 \\
\hline & peritonite (6 horas de evolução) & 85 & 11,7 \\
\hline & desnutrição & 85 & 7 \\
\hline \multirow[t]{2}{*}{ Biondo-Simões e $\mathrm{col}^{26}$} & ÄUSENTE & 20 & 0 \\
\hline & peritonite ( 24 horas de evolução) & 20 & 5 \\
\hline \multirow[t]{4}{*}{ Biondo-Simôes e col $^{28}$} & AUSENTE & 20 & 0 \\
\hline & peritonite (12 horas de evolução) & 17 & 5,9 \\
\hline & peritonite (18 horas de evolução) & 19 & 16 \\
\hline & peritonite (24 horas de evolução) & 19 & 75 \\
\hline
\end{tabular}

No presente estudo não houve nenhum caso de fístula nos animais dos Grupos 0, 1, 2, e 4 (Figura 4). Porém, identificou-se uma pequena deiscência da sutura com bloqueio da gordura do funículo espermático em um rato do Grupo 30 durante necropsia no $4^{\circ}$ dia pós-operatório. Este animal tinha uma contaminação pequena no momento do tratamento da lesão, e a sutura foi feita com 6 pontos, sendo a extensão da lesão de 14 milímetros após terminada a síntese. Talvez uma falha na técnica cirúrgica possa explicar esta complicação, que foi a única $(1,7 \%)$ entre os animais operados num intervalo de até 4 horas. Nos 36 animais tratados a partir da sexta hora após o trauma foi detectada fístula em 8 ratos $(22,2 \%)$, sendo a incidência desta complicação nos Grupos 6, 9 e 12 de, respectivamente, 25, 30 e 42,9\% (Figura 4). Estes valores foram estatisticamente significativos $\left(\mathrm{p}=0,0015^{*}\right)$, sendo que neste modelo animal uma demora maior que 6 horas, para o tratamento do trauma do ceco, foi determinante para a ocorrência de complicações da sutura primária. 
Biondo-Simões e col. ${ }^{23}$ avaliaram a influência do tempo transcorrido entre a lesão e a sutura primária em ratos. A lesão era de aproximadamente $50 \%$ de circunferência da alça, porém no cólon esquerdo, a 4 centímetros da reflexão peritoneal. Como apresentado na Tabela 1 , houve maior incidência de fístula nos animais que apresentavam peritonite e que foram tratados com 18 ou 24 horas após a lesão. Os autores observaram que suturas com mais de 12 horas de evolução da lesão retardam o processo de maturação do colágeno, prejudicando a cicatrização e favorecendo o aparecimento de complicações como deiscências, abscessos intracavitários, peritonite e óbito.

Em relação à ocorrência de fístula em animais tratados com diferentes graus de peritonite, observou-se uma maior incidência desta complicação em ratos com contaminação moderada (50\%) se comparados a animais com contaminação mínima $(7,8 \%)$. Estes resultados também foram estatisticamente significativos $\left(p=0,0046^{*}\right)$. Na literatura existem outras pesquisas com resultados semelhantes, que mostram uma maior incidência de fístula em anastomoses na vigência de peritonite, conforme apresentado no Tabela $1^{10,16,19,20,22}$. Irvin ${ }^{16}$ afirmou que a infecção resulta em mudanças significativas no metabolismo do colágeno durante a fase inicial de cicatrização do cólon suturado, constituindo-se num fator deletério ao processo cicatricial. Leite e col. ${ }^{10}$ estudaram o efeito da peritonite fecal na cicatrização de anastomose do cólon distal de ratos e concluíram que a infecção prolonga a fase latente do processo cicatricial, favorecendo a deiscência das anastomoses.

Nos 70 animais $(77,8 \%)$ em que foi realizada a Biópsia $\mathrm{B}$, em todos havia sinais de peritonite aguda, sendo a intensidade do processo inflamatório graduada como leve na maioria dos animais, exceto em 9 ratos $(12,9 \%)$ biopsiados a partir da quarta hora após o trauma. Nos nove animais que evoluíram com fístula, realizou-se a Biópsia B em $8(88,9 \%)$, sendo que a maioria desses exames (6 ratos - 75\%) mostraram peritonite leve. Ao contrário do que suspeitávamos no início deste estudo, não houve associação entre a intensidade da peritonite aguda encontrada na Biópsia $\mathrm{B}$ e a ocorrência de fístula.

Minossi e col. ${ }^{21}$ avaliaram as alterações anatomopatológicas do cólon distal de ratos submetidos à peritonite induzida através da injeção intraperitoneal de homogeneizado de fezes humanas. Os animais foram estudados após intervalos de 3, 6, 12, 18 e 24 horas e ao exame microscópico todas as peças avaliadas também apresentavam processo inflamatório com infiltrado de polimorfonucleares, que se tornou mais intenso com o passar das horas, até a formação de abscesso peritoneal.

O achado de autólise na análise da Biópsia C em 24 animais (25\%) coincidiu com a evolução a óbito nestes mesmos animais. A deterioração sistêmica do rato devido à infecção abdominal e choque séptico, com má perfusão tecidual, resultaram num processo de degradação progressivo tissular, com um aumento rápido no número de colônias bacterianas no período post-mortem.

A avaliação da Biópsia $\mathrm{C}$ em necropsias realizadas no $1^{\circ}$ e $4^{\circ}$ dia pós-operatório mostrou peritonite em fase aguda ou subaguda, na maioria dos animais com sinais mais intensos de processo inflamatório. Naresse e col. ${ }^{20}$ avaliaram o efeito da peritonite causada pela injeção intraperitoneal de fezes humanas na cicatrização do cólon distal de ratos. O exame microscópico das anastomoses em animais sacrificados no $4^{\circ}$ dia pósoperatório mostrou intensa reação inflamatória polimorfonuclear nos animais do grupo da peritonite, tanto nas bordas da anastomose como no bloqueio do epíploon subjacente. Os autores destacaram que o período em que ocorrem as deiscências corresponde à fase inflamatória da cicatrização, na qual a integridade das bordas depende muito do fio de sutura, com pequena participação do colágeno recém-sintetizado. Naresse e col..$^{20}$ observaram que em animais em que a anastomose foi examinada após 7, 10, 14 e 21 dias, a intensidade das alterações inflamatórias era progressivamente menor. BiondoSimões e col. ${ }^{22}$ encontraram apenas reação inflamatória tipo aguda em cortes histológicos de ratos sacrificados no $3^{\circ}$ dia pós-operatório, tanto do grupo-controle como no da peritonite. Já no $7^{\circ}$ dia estes autores observaram distribuição relativamente igual entre os grupos, com mescla de tipos celulares, de reação aguda e predominantemente crônica. Isto também foi constatado no presente estudo. Além disto, verificou-se o domínio de reação inflamatória em fase crônica nos animais avaliados no $7^{\circ} \mathrm{e} 14^{\circ}$ dia pós-operatório.

Diante do exposto observa-se que, em estudo experimental de sutura primária em lesões traumáticas no ceco de ratos, há uma maior incidência de complicações, em particular fístula intestinal, ao se submeter os animais a dois fatores de risco: tratamento seis horas após a lesão e contaminação de pelo menos um quadrante da cavidade peritoneal. É importante questionar até que ponto estes resultados obtidos em modelo experimental podem ser extrapolados para a prática clínica. Porém, servem de alerta para que cada cirurgião não seja contagiado pelo modismo de se indicar o reparo primário em todas as lesões traumáticas do cólon, independentemente da presença de fatores de risco. A literatura registra que a grande maioria dos pacientes é beneficiada com esta conduta, porém em casos de exceção a colostomia ainda é um procedimento seguro para o paciente.

O presente trabalho abre caminho para que novas pesquisas sejam realizadas neste modelo experimental, podendo avaliar a eficácia da sutura primária em animais expostos a diferentes fatores de risco, tais como choque hipovolêmico e lesões associadas intra-abdominais. Outra perspectiva nesta linha de pesquisa é a análise de diferentes modalidades terapêuticas, entre elas o uso de antibióticos e a oxigenoterapia hiperbárica, na tentativa de melhorar a sobrevida dos animais expostos à peritonite fecal.

\section{Conclusões}

A análise dos resultados deste trabalho permitem concluir que: houve uma maior incidência de deiscência da sutura em animais operados com intervalo de tempo superior a seis horas; a mortalidade não teve associação com o tempo transcorrido entre o trauma e o tratamento em animais operados 
a partir de uma hora após a lesão; houve uma maior incidência de deiscência da sutura em animais operados na vigência de contaminação moderada da cavidade por fezes; e a mortalidade foi determinada por peritonite em estágio avançado, detectada macroscopicamente e no exame histopatológico.

\section{Referências}

1. Stone HH, Fabian TC. Management of perforating colon trauma. Randomization between primary closure and exteriorization. Ann Surg 1979;190:430-6.

2. Chappuis CW, Frey DJ, Dietzen CD, Panetta TP, Buechter KJ, Cohn Jr I. Management of penetrating colon injuries. A prospective radomized trial. Ann Surg 1991;213:492-8.

3. Sasaki LS, Allaben RD, Golwala R, Mittal VK. Primary repair of colon injuries: a prospective randomized study. J Trauma 1995;39:895-901.

4. Gonzalez RP, Merlotti GJ, Holevar MR. Colostomy in penetrating colon injury: is it necessary? J Trauma 1996;41:271-5.

5. Curran TJ, Borzotta AP. Complications of primary repair of colon injury: literature review of 2.964 cases. Am J Surg 1999;177:42-7.

6. Cornwell III EE, Velmahos GC, Berne TV, Murray JA, Chahwan S, Demetriades D. The fate of colonic suture lines in high-risk trauma patients: a prospective analysis. J Am Coll Surg 1998;187:58-63.

7. Murray JA, Demetriades D, Colson M, Song Z, Velmahos GC, Cornwell III EE, Asensio JA, Belzberg H, Berne TV. Colonic ressection in trauma: colostomy versus anastomosis. J Trauma 1999;46:250-4.

8. Fraga GP, Morandin RC, Avelar WM, Freire LMD, Mantovani M. Complicações das lesões do ceco conforme a gravidade da lesão: modelo em ratos. Acta Cir Bras 1999;14(supl.2):48.

9. Kohn DF, Wixson SK, White WI, Benson GI. Anesthesia and analgesia in laboratory animals. 1 ed. Londres, Academic Press, 1997.

10. Leite CVS, Naresse LE, Rodrigues MAM, Kobayasi S. Intestinal healing in protein malnutrition and peritoneal infection in ratis. Acta Cir Bras 1995;10:9-12.

11. Irvin TT, Edwards JP. Comparison of single-layer inverting, twolayer inverting, and everting anastomoses in the rabbit colon. Br J Surg 1973;60:453-7.

12. Hawley PR. Causes and prevention of colonic anastomotic breakdown. Dis Colon Rectum 1973;16:272-7.

13. Irvin TT, Hunt TK. Reappraisal of the healing process of anastomosis of the colon. Surg Gynecol Obstet 1974;138:741-6.

14. Irvin TT, Hunt TK. The effect of trauma on colonic healing. Br J Surg 1974;61:430-6.

15. Matolo NM, Cohen SE, Wolfman Jr EF. Experimental evaluation of primary repair of colonic injuries. Arch Surg 1976;111:78-80.

16. Irvin, TT. Collagen metabolism in infected colonic anastomoses. Surg Gynecol Obstet 1976;143:220-4.

17. Smith SRG, Connolly JC, Crane PW, Gilmore OJA. The effect of surgical drainage materials on colonic healing. Br J Surg 1982;69:153-5.

18. Mantovani M, Iazetti PE, Rizoli SB, Capone Neto A, Basile Filho A, Leonardi LS. Efeitos da oxigenoterapia hiperbárica na peritonite fecal experimental. Rev Col Bras Cir 1989;16:84-6.

19. Czeczko NG, Tebet JR, Muniz JC, Polonio B, Simões JC. Estudo experimental da presença de dreno de penrose ao nível de anastomose colocólica com e sem peritonite. Acta Cir Bras 1992;7:14750 .

20. Naresse LE, Leite CVS, Rodrigues MAM, Angeleli AYO, Minossi JG, Kobayasi S. Efeito da peritonite fecal na cicatrização do cólon distal no rato. Avaliação anatomopatológica, estudo da força de ruptura e da hidroxiprolina tecidual. Acta Cir Bras 1993;8:48-53.

21. Minossi JG, Naresse LE, Leite CVS, Rodrigues MAM, Angeleli MAY, Curi PR, Kobaiasi S. Fecal peritonitis in the rat. Alterations of the distal colon wall. A biomechanical and anatomopthologic estudy. Acta Cir Bras 1994;9:12-5.

22. Biondo-Simões MLP, Greca FH, Ioshi S, Menini CM, El Tawil II, Chin EWK, Stahalschmidt FL, Sperandio Jr CA, Cebrian CFM. Influência do tempo transcorrido entre a lesão do cólon e a síntese no processo de cicatrização. Estudo experimental em ratos. Acta Cir Bras 2000;15(supl.3):24-9.

23. Biondo-Simões MLP, Greca FH, Ioshi S, Menini CM, El Tawil II, Chin EWK, Stahalschmidt FL, Sperandio Jr CA, Cebrian CFM. Influência do tempo transcorrido entre a lesão do cólon e a síntese no processo de cicatrização. Estudo experimental em ratos. Acta Cir Bras 2000;15(supl.3):24-9.

24. Smith SRG, Connolly JC, Gilmore OJA. The effect of faecal loading on colonic anastomotic healing. Br J Surg 1983;70:49-50.

25. Stewart DJ, Matheson NA. Peritoneal lavage in faecal peritonitis in the rat. Br J Surg 1978;65:57-9.

26. Torres OJM, Macedo EL, Melo TCM, Costa JVG, Nunes PMS, Viana RMM, Dietz UA. Peritonite fecal em ratos: eficácia da lavagem da cavidade peritoneal com solução de cloreto de sódio a 0,9\%. Acta Cir Bras 1999;14:65-8.

27. Gambee LP. A single-layer open intestinal anastomosis applicable to the small as well as the large intestine. West J Surg 1951;59:15.

28. Jiborn H, Ahonen J, Zederfeldt B. Healing of experimental colonic anastomoses. The effect of suture technic on collagen concentration in the colonic wall. Am J Surg 1978;135:333-40.

29. Smith SRG, Connolly JC, Gilmore OJA. The effect of faecal loading on colonic anastomotic healing. Br J Surg 1983;70:49-50.

Conflito de interesse: nenhum

Fonte de financiamento: nenhuma

Recebimento: 25/07/2004

Revisão: 20/08/2004

Aprovação: 18/09/2004

\section{Como citar este artigo:}

Fraga GP, Mantovani M, Morandin RC, Gomes CP, Magna LA, Avelar WM, Freire LMD. Fatores de risco no tratamento de lesões do ceco com sutura primária em ratos. Acta Cir Bras [serial online] 2004 Nov-Dez;19(6). Disponível em URL: http:// www.scielo.br/acb [também em CD-ROM].

\section{*Figuras coloridas disponíveis em www.scielo.br/acb}

